\title{
Influence factors and effect prediction model of the tertiary migrations of remaining oil
}

\author{
Rongda Zhang ${ }^{1,2} \cdot$ Guanghui Yang $^{1} \cdot \mathrm{Kang} \mathrm{Ma}^{2} \cdot$ Zhichao Song $^{3} \cdot{\text { Junjian } \mathrm{Li}^{1} \cdot \text { Hanqiao Jiang }}^{1}$
}

Received: 5 August 2020 / Accepted: 10 October 2020 / Published online: 28 October 2020

(c) The Author(s) 2020

\begin{abstract}
Worldwide, for older fields that are in the late stages of production period, production wells that lose production value due to high water cut are usually shut down. In this situation, the remaining oil in the reservoir will be re-enriched under the influence of gravity differentiation and capillary forces. Production practices find when the production well is closed for a long time and then opened for restarting production, the water cut drops dramatically and the output rise sharply. In order to anticipate the effects of enrichment of remaining oil in the reservoir, this paper analyzes 10 influencing factors respectively. Secondly, change of water cut before and after shut-in is used as the evaluation index of residual oil enrichment effect. Numerical simulation method is used to simulate the influence of different factors on the effect of external migrations of remaining oil at different levels. Grey correlation analysis is utilized to rank the correlation of 10 factors on residual oil enrichment and then we can get the main controlling factors affecting residual oil enrichment. Finally, the response surface analysis method is used to establish a 5-factor 3-level model, and the corresponding prediction results are obtained through numerical simulation experiments. The main control factors are fitted to obtain the prediction formula of the remaining oil enrichment effect. As a result, we can use the prediction formula to forecast the enrichment effect of remaining oil under different reservoir parameters.
\end{abstract}

Keywords Remaining oil · Correlation analysis $\cdot$ Prediction model $\cdot$ Response surface analysis

\section{Introduction}

Fault-block reservoirs in China generally enter the late stage of development, and the production cost increases due to the high water cut of production wells (Cui et al. 2017; Kang et al. 2019; Jianmin Wang et al. 2011). Therefore, many

Electronic supplementary material The online version of this article (https://doi.org/10.1007/s13202-020-01023-y) contains supplementary material, which is available to authorized users.

Junjian Li

1395438785@qq.com

Rongda Zhang

rongda.zhang@outlook.com

1 Petroleum Engineering Institute, China University of Petroleum (Beijing), Beijing, China

2 State Key Laboratory of Oil and Gas Resources and Exploration, China University of Petroleum (Beijing), Beijing, China

3 Research Institute of Exploration and Development, SINOPEC Shengli Oilfield, Dongying, China production wells stop to product because of the high water cut and low production value (Han 2010). Yang et al. (2015) point out that residual oil in the formation will enrich under the action of gravity, buoyancy and capillary force. The enrichment process of remaining oil after shut-in is referred to the tertiary migration of remaining oil. Tertiary migration of oil and water means that the water cut of a production well has reached nearly $100 \%$ and the remaining oil is transported under the action of gravity and capillary force under the shut-in method, and the remaining oil accumulation area is formed in fault-block reservoir due to long-time shut-in enrichment. After opening the well, the water cut decrease and the output rise (Benke 2010). Jacot (2015) discusses a method to estimate the internal rock characteristics of the reservoir blocks, when studying the migration efficiency of the residual oil in the abandoned reservoir. Minescu et al. (2010) analyzes the mechanism and influencing factors involved in tertiary migration and introduces two production projects in Romania to prove the effectiveness of tertiary migration. Jacota (2014) discusses tertiary migration from the perspective of gravity differentiation and studies 
the parameters that mainly affect tertiary migration and combines with actual production cases. He points out the importance of gravity differentiation to the enrichment of residual oil. Popa and Jacotă (2016) points out that reservoir physical parameters are changed after a long-time of production and proposed a parameter correction method using linear difference, which does not need a lot of calculation time and can be utilized to the correction of complex models. The role of residual oil in reservoir dispersal are widely studied (Kumar and Mandal 2017; Liu et al. 2019; Nasri and Mozafari 2018; $\mathrm{Xu}$ et al. 2019a, b). But there is still no way to predict the effect of the tertiary migration of remaining oil.

Because there are few examples in the field, this article uses the method of numerical simulation combined with response surface analysis (RSM) and establishes a universal numerical simulation model. Selecting structural high production wells and evaluating the effect of the tertiary migration of remaining oil (TMRO) by observing the changes in water cuts before and after the well is closed. Ten factors affecting the migration of remaining oil in the reservoir are analyzed. The grey correlation analysis method is used to analyze the correlation between the TMRO and ten factors and ranking them. In the end, the five most important factors are selected for orthogonal experiment design and numerical simulation experiments are combined with the RSM method. Finally, the effective prediction formulas of the TMRO under different combinations of influence factors are obtained.

\section{Building a numerical simulation model}

In order to examine the effects of various factors on the enrichment of remaining oil with the numerical simulation methods, a typical numerical simulation model is established. Using Eclipse software to build a typical numerical simulation model. For the convenience of research, there is one injection well and one production well in the production mode of the model reservoir and the model with a certain inclination. The water injection is in the lower part and oil production in the upper part until the water cut of the production well reaches $95 \%$. The remaining oil will move upward after the well is closed. After several years, the well is opened for production again. The change of the water cut is used to evaluate the effect of the tertiary migrations of the remaining oil. The numerical simulation model is given in Fig. 1. The model parameters are shown in Table 1, and the model's relative permeability and capillary force curves are shown in Fig. 2.

After analysis, we believe that the factors affecting the TMRO including formation dip, formation permeability, borehole time, water body energy, oil viscosity, reservoir thickness, oil-water well spacing, capillary force, oil density, the distance between the well and the high part of the

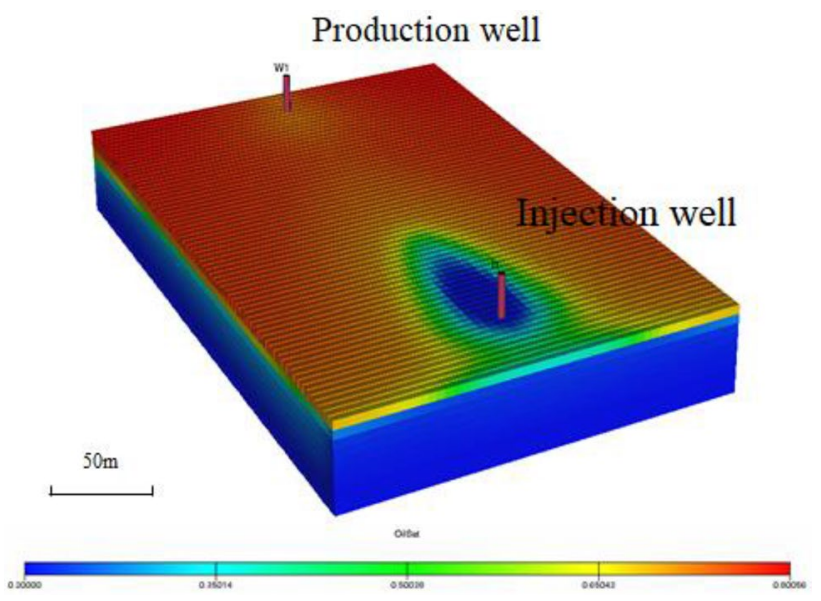

Fig. 1 Oil saturation profile of the model

reservoir. Each factor is analyzed separately. In order to clarify the effect of each factor on the TMRO process, an analysis and evaluation of method as showed in Table 2 is developed.

The numerical simulation method is used to simulate the schemes in Table 2 one by one, and the effects of tertiary migration of residual oil before and after shut-in at different factors at different levels are obtained.

\section{Grey relational analysis}

In order to further simplify the variables, this article uses the grey correlation analysis method to analyze and obtain the correlation between each factor and the effect of the TMRO and ranks them. Finally, the influencing factors are optimized according to the ranking.

Grey correlation analysis method is a multi-factor comparative analysis method, which is in essence the analysis of curve development and change trend (Wang et al. 2020). It describes the strength, size and order of the relationship among factors based on the sample data of each factor by the grey correlation degree. If the sample data column reflects the change tendency (direction, size and speed, etc.) of the two factors are basically the same, then they have a greater correlation. On the contrary, the correlation degree is small. Compared with traditional multi-factor analysis methods (correlation, regression, etc.), grey correlation analysis requires less data and less calculation. So it is easy to be widely used. Using the grey correlation analysis needs to go through the following steps:

\section{(1) Data pre-processing}

On the basis of qualitative analysis of the problem studied, one dependent variable and several independent 
Table 1 Numerical simulation model parameters

\begin{tabular}{llll}
\hline Geological parameter & Value & Fluid parameter & Value \\
\hline Initial oil saturation $(\%)$ & 64 & Density of oil phase $\left(\mathrm{kg} / \mathrm{m}^{3}\right)$ & 836 \\
Permeability $\left(\times 10^{-3} \mu \mathrm{m}^{2}\right)$ & 800 & Density of water phase $\left(\mathrm{kg} / \mathrm{m}^{3}\right)$ & 1000 \\
Injection pressure $(\mathrm{MPa})$ & 33 & Viscosity of water phase $(\mathrm{mPa} \cdot \mathrm{s})$ & 1 \\
Production pressure $(\mathrm{MPa})$ & 27 & Viscosity of oil phase $(\mathrm{mPa} \mathrm{s})$ & 10 \\
Original pressure $(\mathrm{MPa})$ & 30 & Volume factor of oil phase $\left(\mathrm{m}^{3} / \mathrm{m}^{3}\right)$ & 0.988 \\
Grid quantity & $70 \times 50 \times 10$ & Volume factor of water phase $\left(\mathrm{m}^{3} / \mathrm{m}^{3}\right)$ & 1 \\
\hline
\end{tabular}

Fig. 2 Model permeability curve

Table 2 Influence factor parameter

\begin{tabular}{lllll}
\hline No. & Indicator & Parameters & Default & Evaluation index \\
\hline 1 & Dip angle/ $^{\circ}$ & $1,5,10,15,25$ & 15 & ${\text { Enrichment effect }=\mathrm{fw}_{1}-\mathrm{fw}_{2}}_{2}$ water cut before shut in - water cut after reproduction \\
2 & ${\text { Zone permeability } / 10^{-3} \mu \mathrm{m}^{2}}$ & $50,200,500,1000,1500$ & 700 & \\
3 & Well downtime $/$ Year & $0.5,3,5,10,15$ & 10 & \\
4 & Aquifer/Water volume & $10,20,30,40,50$ & 20 & \\
5 & Viscosity/mPa·s & $1,10,20,30,40$ & 10 & \\
6 & Reservoir thickness $/ \mathrm{m}$ & $2,5,10,15,20$ & 10 & \\
7 & Injector producer distance $/ \mathrm{m}$ & $20,40,60,80,100$ & 80 & \\
8 & Capillary $(\mathrm{Pc} 50) / \mathrm{MPa}$ & $0.005,0.01,0.015,0.02,0.025$ & 0.015 & \\
9 & Crude oil density $/\left(\mathrm{g} / \mathrm{cm}^{3}\right)$ & $0.7,0.75,0.8,0.85,0.9$ & 0.8 & \\
10 & Distance between well and & $20,40,60,80,100$ & 100 & \\
& reservoir top $/ \mathrm{m}$ & & & \\
\hline
\end{tabular}

variables are determined. Assuming that there are m evaluation objects and $\mathrm{n}$ included evaluation indexes, the data set of $n$ evaluation indexes of $m$ evaluation objects can form the following evaluation matrix:

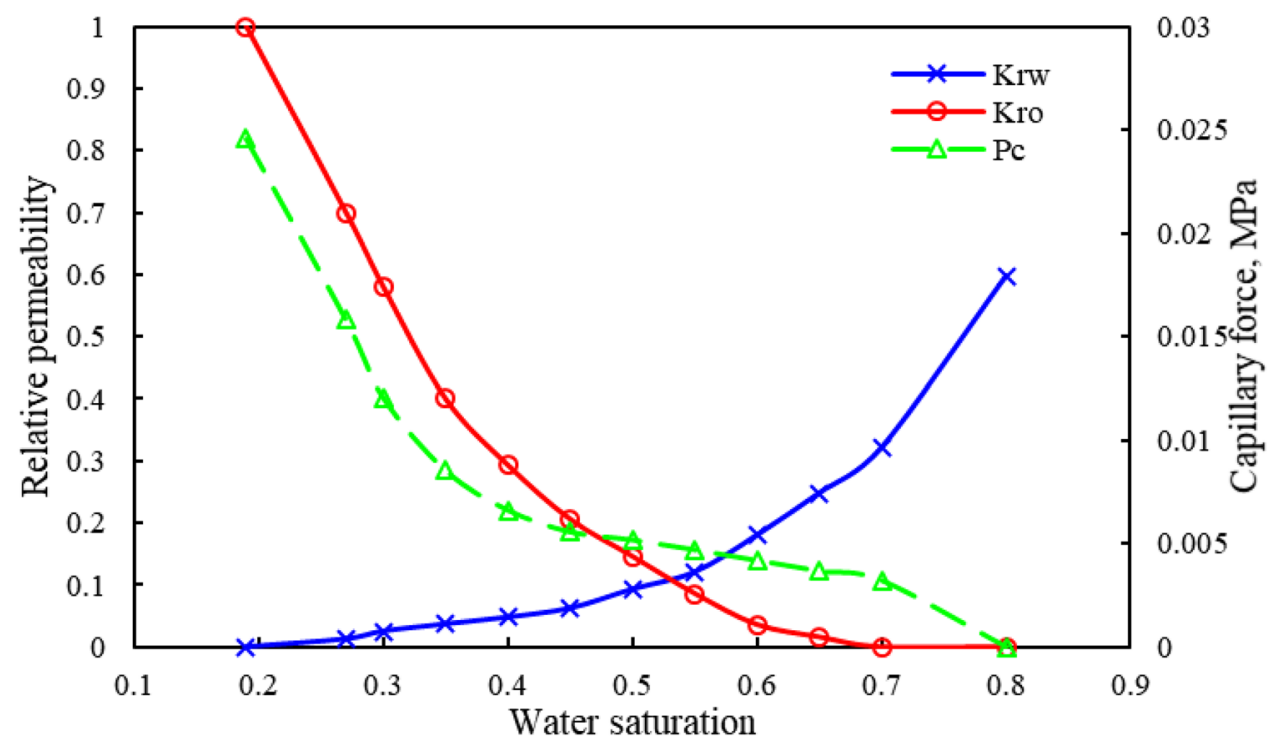


In general, the original variable sequence has different dimensions or orders of magnitude. In order to ensure the reliability of the analysis results, the variable sequence needs to be dimensionless. After dimensionless, each factor sequence forms the Eq. (2):

$\left(X_{0}, X_{1}, \ldots, X_{m}\right)=\left[\begin{array}{cccc}x_{0}(1) & x_{1}(1) & \cdots & x_{m}(1) \\ x_{0}(2) & x_{1}(2) & \cdots & x_{m}(2) \\ \vdots & \vdots & & \vdots \\ x_{0}(n) & x_{1}(n) & \cdots & x_{m}(n)\end{array}\right]_{n \times(m+1)}$

\section{(2) Calculating the incidence matrix}

Calculating the absolute difference between the first column and the rest of the sequence in Eq. (2) and from the absolute difference matrix, as showed in Eq. (3).

$\left[\begin{array}{cccc}\Delta_{01}(1) & \Delta_{02}(1) & \cdots & \Delta_{0 m}(1) \\ \Delta_{01}(2) & \Delta_{02}(2) & \cdots & \Delta_{0 m}(2) \\ \vdots & \vdots & & \vdots \\ \Delta_{01}(n) & \Delta_{02}(n) & \cdots & \Delta_{0 m}(n)\end{array}\right]_{n \times m}$

The data in the absolute difference matrix are transformed as Eq. (4):

$\xi_{0 i}(\mathrm{k})=\frac{\Delta(\min )+\rho \Delta(\max )}{\Delta_{0 i}(k)+\rho \Delta(\max )}$

The matrix for correlation coefficient is:

$\left[\begin{array}{cccc}\xi_{01}(1) & \xi_{02}(1) & \cdots & \xi_{0 m}(1) \\ \xi_{01}(2) & \xi_{02}(2) & \cdots & \xi_{0 m}(2) \\ \vdots & \vdots & & \vdots \\ \xi_{01}(n) & \xi_{02}(n) & \cdots & \xi_{0 m}(n)\end{array}\right]_{n \times m}$

In the formula, the value of the resolution coefficient $p$ is in $(0,1)$; the smaller $\mathrm{p}$ is, the higher the difference of the correlation coefficient. The correlation coefficient $\xi_{0 i}(k)$ is a positive number no more than 1 . The smaller $\Delta_{0 i}(k)$ is, the larger $\xi_{0 i}(k)$ is. It reflects the degree of correlation between the comparison sequence $X_{0}$ and the reference sequence.

\section{(3) Calculation of correlation}

The degree of correlation between the comparison sequence $X_{i}$ and the reference sequence $X_{0}$ is reflected by $\mathrm{N}$ correlation coefficients (i.e., column i in Eq. (2)), and the correlation degree of $X_{i}$ and $X_{0}$ can be obtained by averaging, as showed in Eq. (6):

$r_{0 i}=\frac{1}{\mathrm{n}} \sum_{k=1}^{n} \xi_{0 i}(k)$
Table 3 The correlation degree between enrichment effect and the input feature

\begin{tabular}{llll}
\hline No & Indicator name & $\begin{array}{l}\text { Coefficient of } \\
\text { association }\end{array}$ & Rank \\
\hline F1 & Dip angle & 0.821 & 5 \\
F2 & Zone permeability & 0.942 & 2 \\
F3 & Well downtime & 0.975 & 1 \\
F4 & Aquifer & 0.481 & 10 \\
F5 & Viscosity of crude oil & 0.868 & 4 \\
F6 & Reservoir thickness & 0.497 & 9 \\
F7 & Injector producer distance & 0.709 & 6 \\
F8 & Capillary (Pc50) & 0.636 & 7 \\
F9 & Crude oil density & 0.921 & 3 \\
F10 & Distance between well and & 0.563 & 8 \\
& reservoir top & & \\
\hline
\end{tabular}

The higher the correlation degree is, the more consistent the change trend is between the comparison sequence and the reference sequence.

The change of water cut of production well before and after shut-in enrichment is used to evaluate the effect of TMRO. By using typical model and numerical simulation method, according to the parameters selected in Table 2 and by controlling other conditions to remain unchanged, the degree of TMRO corresponding to the changes of various factors is investigated respectively. Finally, the correlation between the variation of each factor and the effect of TMRO is discussed by using the grey correlation analysis method. Correlation degree and correlation rank between production decline and various influencing factors are shown in Table 3.

\section{Multi-factor response surface analysis}

We select the factors with a correlation of more than 0.8 with the effect of TMRO as the main control factors. The five most significant factors are selected and invoked as the main factors for analysis. In order to quantify the enrichment effect. The method of RSM is used to simulate the main effects and interactions of the five main controlling factors of borehole time, permeability, oil density, oil viscosity, and

Table 4 Orthogonal experimental design

\begin{tabular}{lllll}
\hline Indicator & Coded value & \multicolumn{2}{l}{$\begin{array}{l}\text { Value of each level } \\
\text { encoding }\end{array}$} \\
\cline { 3 - 5 } & & -1 & 0 & 1 \\
\hline Well downtime $/$ year & $\mathrm{A}$ & 0.5 & 7.75 & 15 \\
Permeability $/ \times 10^{-3} \mu \mathrm{m}^{2}$ & $\mathrm{~B}$ & 50 & 1025 & 2000 \\
Oil density $/\left(\mathrm{g} / \mathrm{cm}^{3}\right)$ & $\mathrm{C}$ & 0.7 & 0.825 & 0.95 \\
Viscosity of oil/ $\mathrm{mPa} \cdot \mathrm{s}$ & $\mathrm{D}$ & 5 & 15 & 25 \\
Dip angle $/{ }^{\circ}$ & $\mathrm{E}$ & 1 & 25.5 & 50 \\
\hline
\end{tabular}


formation dip angle of the TMRO under different conditions. Box-Behnken response surface optimization experiment design was adopted, and the center composite design is performed at three levels of low, medium and high. The relationship between the 5 factor 3 level coding and the experimental values is shown in Table 4, and the experimental scheme and results are shown in Table 5.

The experimental results of the table are analyzed by the software DESIGN EXPERTS10 and the details of calculation method and process are shown in the appendix. The results are shown in Table 6 in the next section.

\section{Model evaluation}

Figure 3a shows the normalized residual diagram of the model. We can see that these points follow a line. Therefore, residuals follow a normal distribution. Figure $3 b$ indicates
Table 5 Orthogonal experiment results

\begin{tabular}{|c|c|c|c|c|c|c|}
\hline $\begin{array}{l}\text { Sequence } \\
\text { Number }\end{array}$ & $\begin{array}{l}\text { Well down- } \\
\text { time (years) }\end{array}$ & $\begin{array}{l}\text { Permeability } \\
\left(10^{-3} \mu \mathrm{m}^{2}\right)\end{array}$ & $\begin{array}{l}\text { Density of Oil } \\
\left(\mathrm{g} / \mathrm{cm}^{3}\right)\end{array}$ & Angel $\left(^{\circ}\right)$ & $\begin{array}{l}\text { Viscosity } \\
(\mathrm{mPa} \cdot \mathrm{s})\end{array}$ & $\begin{array}{l}\text { Water cut } \\
\text { change }(\%)\end{array}$ \\
\hline 1 & 7.75 & 2000 & 0.95 & 15 & 25.5 & 4.68 \\
\hline 2 & 15 & 1025 & 0.825 & 25 & 25.5 & 3.00 \\
\hline 3 & 0.5 & 1025 & 0.95 & 15 & 25.5 & 24.68 \\
\hline 4 & 7.75 & 2000 & 0.825 & 5 & 25.5 & 1.20 \\
\hline 5 & 7.75 & 1025 & 0.7 & 25 & 25.5 & 1.87 \\
\hline 6 & 7.75 & 1025 & 0.7 & 15 & 1 & 24.66 \\
\hline 7 & 15 & 1025 & 0.95 & 15 & 25.5 & 15.04 \\
\hline 8 & 0.5 & 1025 & 0.825 & 5 & 25.5 & 17.45 \\
\hline 9 & 7.75 & 2000 & 0.825 & 25 & 25.5 & 32.73 \\
\hline 10 & 0.5 & 2000 & 0.825 & 15 & 25.5 & 28.58 \\
\hline 11 & 7.75 & 1025 & 0.825 & 15 & 25.5 & 35.86 \\
\hline 12 & 7.75 & 1025 & 0.7 & 5 & 25.5 & 43.06 \\
\hline 13 & 7.75 & 1025 & 0.825 & 15 & 25.5 & 45.50 \\
\hline 14 & 0.5 & 50 & 0.825 & 15 & 25.5 & 14.96 \\
\hline 15 & 7.75 & 50 & 0.95 & 15 & 25.5 & 18.93 \\
\hline 16 & 0.5 & 1025 & 0.825 & 15 & 50 & 14.96 \\
\hline 17 & 7.75 & 50 & 0.825 & 25 & 25.5 & 2.84 \\
\hline 18 & 7.75 & 1025 & 0.95 & 15 & 50 & 15.60 \\
\hline 19 & 15 & 1025 & 0.825 & 15 & 50 & 9.93 \\
\hline 20 & 7.75 & 1025 & 0.95 & 5 & 25.5 & 8.58 \\
\hline 21 & 7.75 & 1025 & 0.95 & 15 & 1 & 32.71 \\
\hline 22 & 7.75 & 1025 & 0.95 & 25 & 25.5 & 25.50 \\
\hline 23 & 7.75 & 50 & 0.825 & 15 & 1 & 22.81 \\
\hline 24 & 7.75 & 1025 & 0.825 & 25 & 50 & 22.69 \\
\hline 25 & 7.75 & 2000 & 0.825 & 15 & 50 & 29.92 \\
\hline 26 & 7.75 & 50 & 0.7 & 15 & 25.5 & 13.19 \\
\hline 27 & 7.75 & 50 & 0.825 & 5 & 25.5 & 0.60 \\
\hline 28 & 7.75 & 1025 & 0.825 & 5 & 1 & 28.55 \\
\hline 29 & 7.75 & 50 & 0.825 & 15 & 50 & 0.03 \\
\hline 30 & 7.75 & 2000 & 0.7 & 15 & 25.5 & 43.08 \\
\hline 31 & 7.75 & 1025 & 0.825 & 5 & 50 & 5.77 \\
\hline 32 & 7.75 & 1025 & 0.825 & 15 & 25.5 & 14.96 \\
\hline 33 & 7.75 & 1025 & 0.825 & 15 & 25.5 & 14.96 \\
\hline 34 & 7.75 & 2000 & 0.825 & 15 & 1 & 52.70 \\
\hline 35 & 7.75 & 1025 & 0.7 & 15 & 50 & 20.28 \\
\hline 36 & 15 & 1025 & 0.7 & 15 & 25.5 & 14.96 \\
\hline 37 & 0.5 & 1025 & 0.825 & 15 & 1 & 14.96 \\
\hline 38 & 15 & 50 & 0.825 & 15 & 25.5 & 45.48 \\
\hline 39 & 7.75 & 1025 & 0.825 & 15 & 25.5 & 35.78 \\
\hline 40 & 15 & 1025 & 0.825 & 5 & 25.5 & 23.01 \\
\hline
\end{tabular}


Table 6 Response surface analysis

\begin{tabular}{llllll}
\hline Source & $\begin{array}{l}\text { Sum of } \\
\text { Squares }\end{array}$ & $d f$ & $\begin{array}{l}\text { Mean } \\
\text { Square }\end{array}$ & $F$ value & $p$ value \\
\hline Model & 8696.657 & 20 & 434.8328 & 583.7187 & $1.58 \mathrm{E}-28$ \\
A-Time & 1185.805 & 1 & 1185.805 & 1591.823 & $3.7 \mathrm{E}-24$ \\
B-Permea- & 3329.814 & 1 & 3329.814 & 4469.935 & $1.04 \mathrm{E}-29$ \\
bility & & & & & \\
C-Oil den- & 428.6414 & 1 & 428.6414 & 575.4073 & $8.93 \mathrm{E}-19$ \\
sity & & & & & \\
D-Dip angle & 1072.38 & 1 & 1072.38 & 1439.56 & $1.27 \mathrm{E}-23$ \\
E-Viscosity & 2076.317 & 1 & 2076.317 & 2787.243 & $3.64 \mathrm{E}-27$ \\
AB & 10.29177 & 1 & 10.29177 & 13.81566 & 0.001021 \\
AC & 0 & 1 & 0 & 0 & 1 \\
AD & 1.529285 & 1 & 1.529285 & 2.052909 & 0.164303 \\
AE & 0 & 1 & 0 & 0 & 1 \\
BC & 0 & 1 & 0 & 0 & 1 \\
BD & 0.920034 & 1 & 0.920034 & 1.235051 & 0.277001 \\
BE & 0 & 1 & 0 & 0 & 1 \\
CD & 0 & 1 & 0 & 0 & 1 \\
CE & 0 & 1 & 0 & 0 & 1 \\
DE & 0 & 1 & 0 & 0 & 1 \\
A $^{\wedge} 2$ & 2.320306 & 1 & 2.320306 & 3.114774 & 0.0898 \\
B $^{\wedge} 2$ & 169.488 & 1 & 169.488 & 227.5204 & $4.62 \mathrm{E}-14$ \\
$\mathrm{C}^{\wedge} 2$ & 128.7313 & 1 & 128.7313 & 172.8086 & $9.93 \mathrm{E}-13$ \\
$\mathrm{D}^{\wedge} 2$ & 97.09046 & 1 & 97.09046 & 130.334 & $2.08 \mathrm{E}-11$ \\
$\mathrm{E}^{\wedge} 2$ & 458.0931 & 1 & 458.0931 & 614.9433 & $4.02 \mathrm{E}-19$ \\
Residual & 18.62339 & 25 & 0.744936 & & \\
Lack of Fit & 18.62339 & 20 & 0.931169 & & \\
Pure Error & 0 & 5 & 0 & & \\
Cor Total & 8715.28 & 45 & & & \\
\hline & & & & & \\
\hline & & & & \\
\hline
\end{tabular}

the relationship between model residuals and predicted values. These points are within the constant range of the whole graph, indicating that the model is very suitable for experimental data.

Figure 4 shows the relationship between the experimental data of the model and the predicted values. These points can be observed on a line, which makes the model suitable for experimental data.

Figure 5 displays a 2D profile and 3D surface view of the impact of shut-in time and reservoir permeability on the predicted response. Other parameters are constant at the mean value (oil density: $0.825 \mathrm{~g} / \mathrm{cm}^{3}$, formation inclination: $15^{\circ}$, oil viscosity: $25.5 \mathrm{mPa} \cdot \mathrm{s}$ ). The longitudinal level in Fig. $5 \mathrm{~b}$ represents the change of water cut before and after enrichment, which also represents the effect of TMRO. With the rise of Permeability and Time, the plane in Fig. 5b gradually rise in the longitudinal direction, which means that TMRO will get better and better with the rise of reservoir Permeability and Time. According to the results of Fig. 5b, the best residual oil enrichment occurred at the maximum well downtime (15 year) and maximum reservoir permeability $\left(2000 \times 10^{-3} \mu \mathrm{m}^{2}\right)$.

Figure 6 shows the 2D contour and 3D surface diagram of the influence of the density of the crude oil and dip Angle of the formation on the prediction of the TMRO. Other parameters are constant at the mean value (shut-in time:7.75 year, reservoir permeability: $1025 \times 10^{-3} \mu \mathrm{m}^{2}$, oil viscosity: $25.5 \mathrm{mPa} \cdot \mathrm{s})$. It can be observed that the increase of dip Angle and the decrease of oil density lead to the significant increase in the effect of TMRO. The profile curvature reflects the significant impact of these two parameters. According to the results of Fig. 6b, the best effect of migration occurred at the maximum formation dip angle $\left(25^{\circ}\right)$ and the minimum oil density $\left(0.7 \mathrm{~g} / \mathrm{cm}^{3}\right)$.

Figure 7 shows a 2D profile and a 3D surface diagram of the effects of shut-in time and oil viscosity on the predicted response. Other parameters are constant at the mean value (reservoir permeability: $1025 \times 10^{-3} \mu \mathrm{m}^{2}$, oil density: $0.825 \mathrm{~g} / \mathrm{cm}^{3}$, formation inclination: $\left.15^{\circ}\right)$. It can be seen that the increase of shut-in time and the decrease of oil viscosity will significantly increase the effect of migration of remaining oil. The profile curvature reflects the significant influence of these two parameters. According to the results of Fig. $7 \mathrm{~b}$, the best effect of oil migration occurred at the maximum well downtime (15 year) and minimum oil viscosity (1 mPa.s).

The analysis results of the response surface method are consistent with the theoretical knowledge and it also reflects the reliability of the calculated data in the model. The calculation also shows the statistical parameters between the variables quantitatively in Table 6. In response surface analysis, the statistical significance of statistical results is measured using the F-value, and the significance of each regression coefficient is detected using the $p$ value. The smaller the $p$ value, the more significant the result. The Model $\mathrm{F}$ value of 583.72 implies the model is significant. There is only a $0.01 \%$ chance that an F-value this large can occur due to noise. The $\mathrm{p}$ value is less than 0.0001 , indicating that the model is significant adaptability, and the nonlinear equation relationship between the factors represented by the regression equation and the response value is significant. The model determination coefficient $R^{2}=0.9979$ means only $0.021 \%$ on the surface cannot be attributed to the regression model. The coefficient of variation $\mathrm{CV}=3.98 \%$ which is smaller than $10 \%$. And the signal-to-noise ratio is 92.561 and it is bigger than 4, which means the model is highly reliable, and the model can be utilized to the expected optimization prediction experiment.

In Table 6, it is found that the p-value of some quadratic terms is greater than 0.05 , which is a non-significant factor. In order to make the expression of the regression equation more concise, the change of the water cut before and after the well closure is taken as the response value, and 
the borehole time, formation permeability, crude oil density, crude oil viscosity, and formation dip angle are independent variables, and terms with $p$ value greater than 0.05 are ignored. Establish a response surface quadratic polynomial, as showing in Eq. (7):

Fig. 3 a Normal plot of residuals, b Relationship between model residuals and predicted values

$$
\begin{aligned}
\Delta f w= & 215.98788+0.67486 t+2.7963 \times 10^{-3} K \\
& -446.978 \rho_{o}-0.29846 \alpha-1.08053 \mu \\
& +2.269 \times 10^{-4} t K+4.63576 \times 10^{-6} K^{2} \\
& +245.8 \rho_{o}^{2}+0.033354 \alpha^{2}+0.01207 \mu^{2}
\end{aligned}
$$

where $\Delta f w$ means change in water cut before and after shutin, $t$ means well boring time (year), $K$ means permeability $\left(10^{-3} \mu \mathrm{m}^{2}\right), \alpha$ means dip angle $\left(^{\circ}\right), \rho_{\mathrm{o}}$ means the density of oil $\left(\mathrm{g} / \mathrm{cm}^{3}\right), \mu$ means the viscosity of oil (mPa.s).

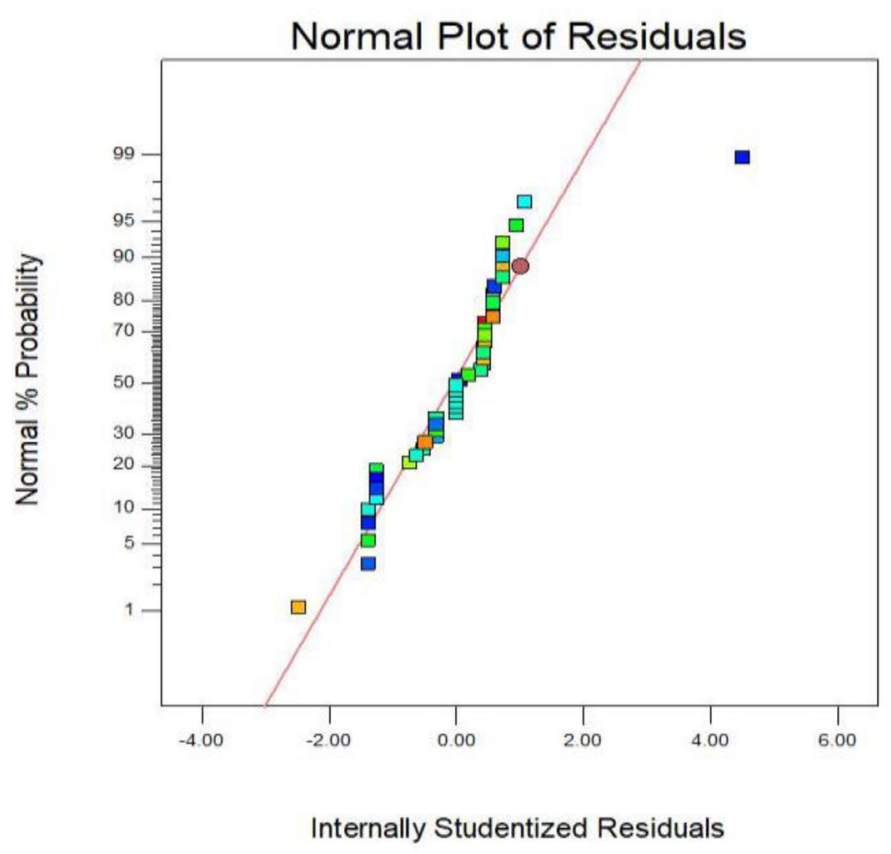

Design-Expert?Software Water cut change

Color points by value of Water cut change:

52.7042

0.0268076

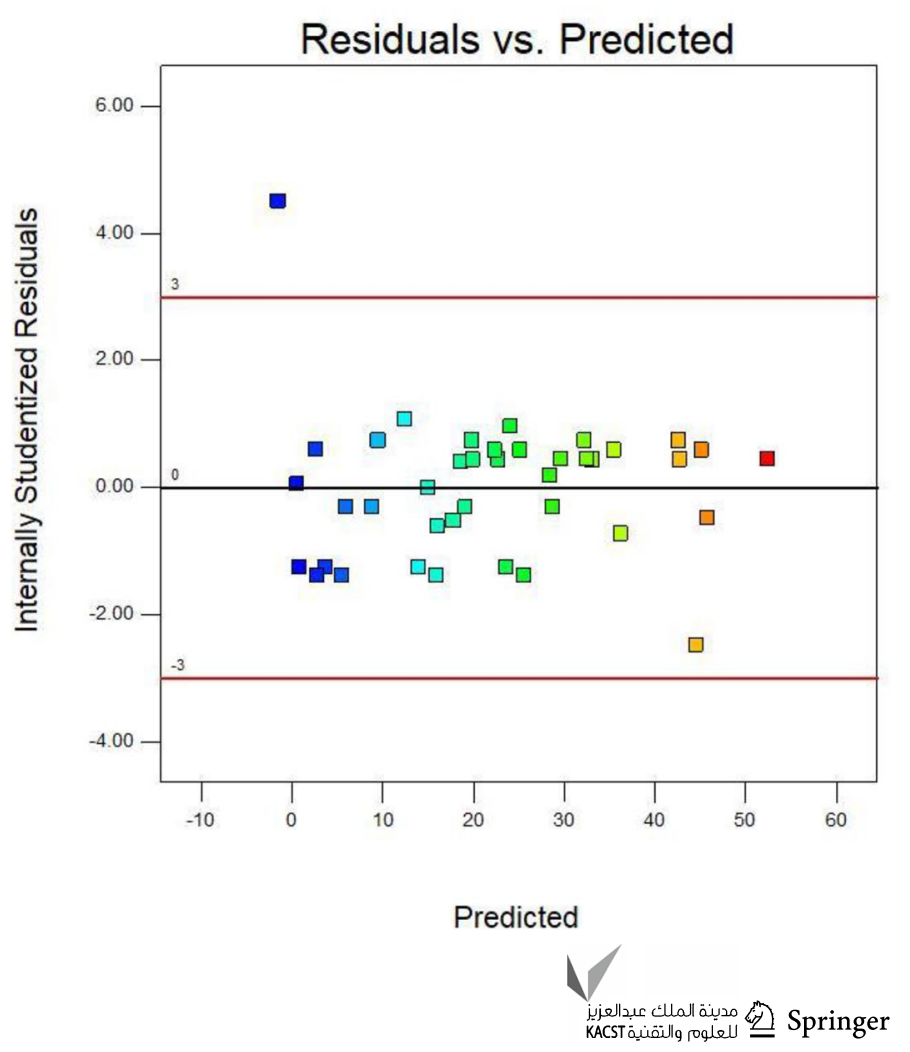




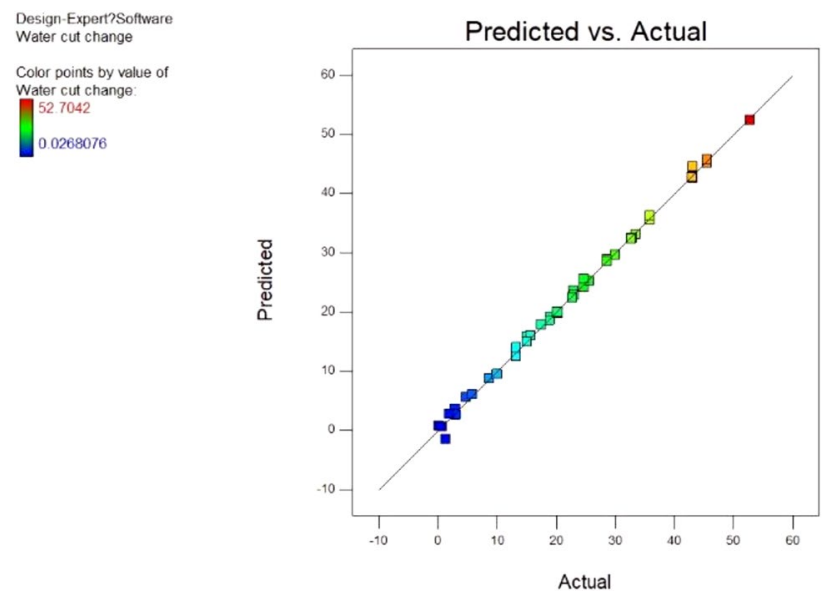

Fig. 4 Experimental data and predicted values of the model

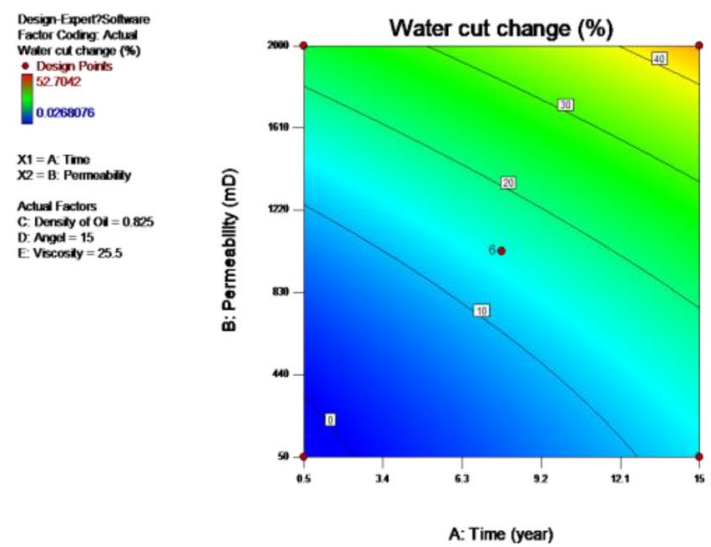

\section{Field application of predictive model}

So far, few specific experiments have been conducted to verify the effects of TMRO. This has only been done in Shengli oilfield in China In this situation, production practice data of Shengli oilfield in eastern China are selected to test the prediction model of residual oil enrichment. Three wells including Well-xie-2-23, Well-xin-47 and Well-xin-18-1 are selected. All three wells are closed due to high water cut. Some years later, the water cut decreases and the production increases. Specific data and fitting are given in Table 7.

After inputting the physical property data and shut-in time data of the three observation wells into Eq. (7), TMRO effect prediction of three wells are made. After calculation, it is found that the predicted TMRO effect is very close to the actual value, and the error value of all three wells are within $7 \%$. Through case analysis in Table 7 , it is proved that the effect prediction formula of residual oil obtained through the above analysis process is certain practicability. For wells

Fig. 5 The effects of well downtime and reservoir permeability on the TMRO. a Contour map. b The response surface figure
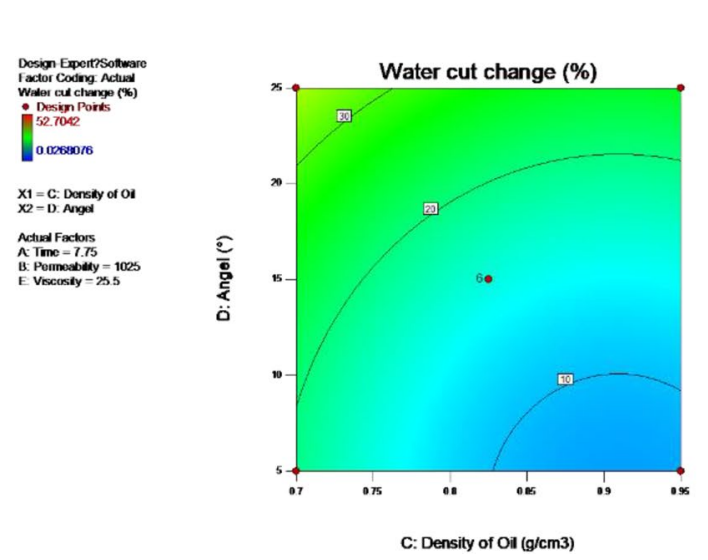

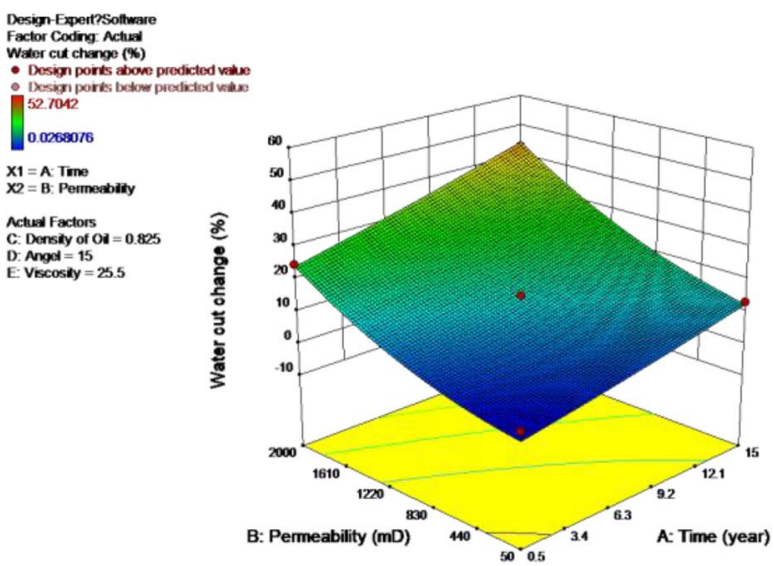

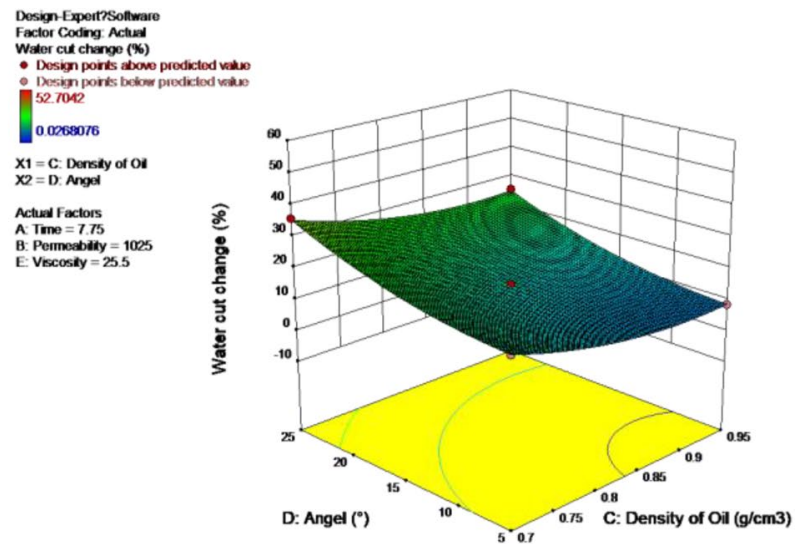

Fig. 6 The influence of crude oil density and dip angle on the TMRO a Contour map. b The response surface figure 

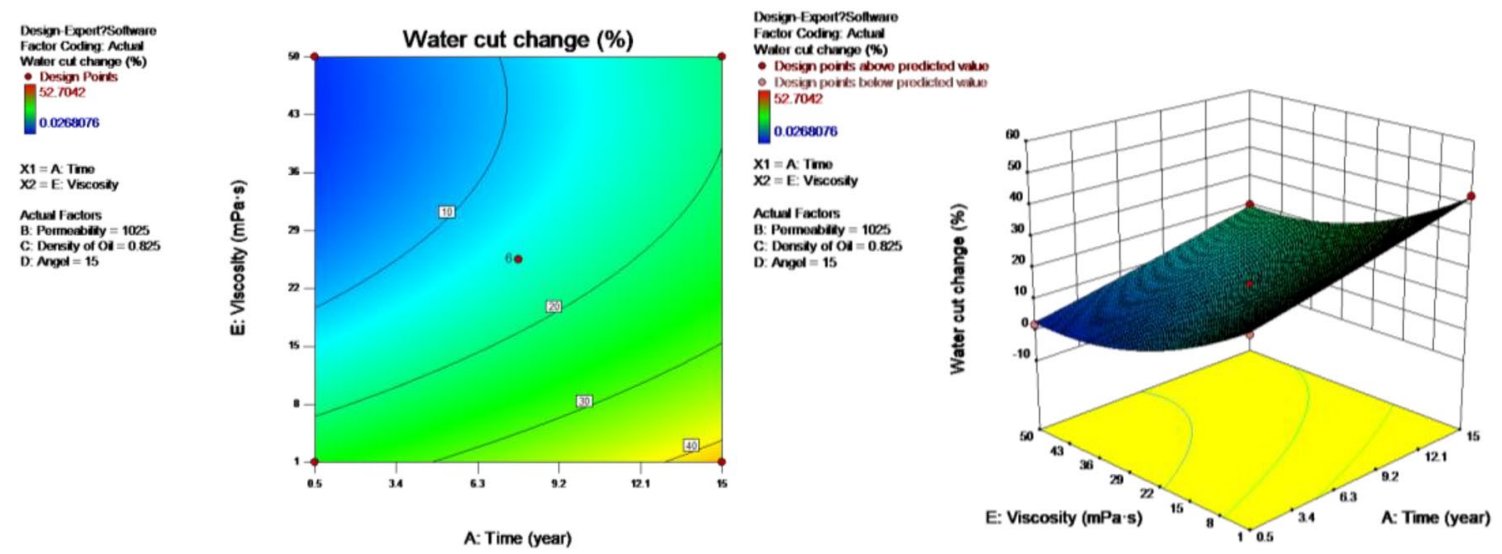

Fig. 7 The effects of well downtime and crude oil viscosity on the TMRO. a Contour map. b The response surface figure

Table 7 Comparison of model prediction results with actual data

\begin{tabular}{lllllllll}
\hline Well & $T$ (years) & $\mathrm{K}\left(10^{-3} \mu \mathrm{m}^{2}\right)$ & $\rho_{\mathrm{o}}\left(\mathrm{g} / \mathrm{cm}^{3}\right)$ & $\mu(\mathrm{mPa} \cdot \mathrm{s})$ & $\alpha\left(^{\circ}\right)$ & Actual value & $\begin{array}{l}\text { Model pre- } \\
\text { dicted value } \\
(\%)\end{array}$ & $\begin{array}{l}\text { Relative } \\
\text { error (\%) }\end{array}$ \\
\hline Xie-2-23 & 12 & 1012 & 0.81 & 17 & 11 & $21 \%$ & 19.64 & 6.48 \\
Xin-47 & 1 & 550 & 0.88 & 15 & 6.2 & $2.80 \%$ & 2.67 & 4.64 \\
Xin-18-1 & 8 & 204 & 0.907 & 12 & 12.5 & $9.8 \%$ & 9.57 & 2.35 \\
\hline
\end{tabular}

with extremely high water cut and shut down, the TMRO effect after a period of time can be predicted according to the prediction method and the formation physical properties. This makes it possible to predict the TMRO effects of different wells and to select wells with enrichment potential to reopen them so that they can create greater value for the field.

\section{Conclusion}

The prediction method of formation TMRO effect is discussed for the first time in this paper. First, a typical numerical simulation model is established, and the influence of different factors on TMRO effect at different values is simulated by numerical simulation method. According to the results of numerical simulation, the main control factors affecting TMRO are analyzed by using grey correlation analysis method. The orthogonal experiment of 5 factors and 3 levels is designed by using RSM method. A series of numerical simulation experiments are carried out by using numerical simulation and RSM methods, and the effects of different combinations of shut-in time, permeability, crude oil density, crude oil viscosity and formation dip angle on TMRO effect are discussed. Finally, the prediction method of TMRO is obtained through RSM method, which can input the physical parameters around the well and the shutin time to predict the effect of TMRO. And through a series of examples for comparative verification. It is proved that the prediction accuracy of this method is high, and it is valuable to be applied.

Acknowledgements This research is supported by the National Major Science and Technology Projects of China (Grant Nos. 2016ZX05011002 and 2016ZX05011-002-002). The authors also wish to appreciate the State Key Laboratory of Oil and Gas Resources and Exploration, China University of Petroleum-Beijing for the permission to publish this paper.

Open Access This article is licensed under a Creative Commons Attribution 4.0 International License, which permits use, sharing, adaptation, distribution and reproduction in any medium or format, as long as you give appropriate credit to the original author(s) and the source, provide a link to the Creative Commons licence, and indicate if changes were made. The images or other third party material in this article are included in the article's Creative Commons licence, unless indicated otherwise in a credit line to the material. If material is not included in the article's Creative Commons licence and your intended use is not permitted by statutory regulation or exceeds the permitted use, you will need to obtain permission directly from the copyright holder. To view a copy of this licence, visit http://creativecommons.org/licenses/by/4.0/.

\section{References}

Abdulredha MM, Hussain SA, Abdullah LC (2020) Optimization of the demulsification of water in oil emulsion via non-ionic surfactant by the response surface methods. J Petrol Sci Eng 184(2019):106463

Al-Ameri TK, Al-Marsoumi SW, Al-Musawi FA (2015) Crude oil characterization, molecular affinity, and migration pathways of

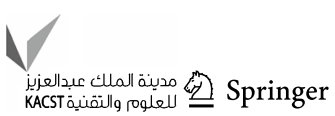


Halfaya oil field in Mesan Governorate South Iraq. Arab J Geosci 8(9):7041-7058

Al-Ameri TK (2015) Oil biomarkers, isotopes, and palynofacies are used for petroleum system type (Irani and Mehrnia et al., 2011; Ani and Ochin, 2018; Memon and Hartadi Sutanto et al., 2020; Singh and Kumar, 2020; Wang and Guan et al., 2020) and migration pathway assessments of Iraqi oil fields. Arab J Geosci 8(8):5809-5831

Alizadeh B, Seyedali SR, Sarafdokht H (2019) Effect of bitumen and migrated oil on hydrocarbon generation kinetic parameters derived from Rock-Eval pyrolysis. Pet Sci Technol 37(20):2114-2121

Benke Li (2008) Study on the Distribution of Reenrichment Part of Remaining Oil in Shuanghe Oilfield. J Oil Gas Technol 30(5):296-298

Bixin L, Jirui H, Hongjiao T, Haixia X (2011) Experimental investigation on binary compound system performance changes during migration. Pet Sci Technol 29(15):1539-1545

Cui M, Wang R, Lv C, Tang Y (2017) Research on microscopic oil displacement mechanism of $\mathrm{CO} 2 \mathrm{EOR}$ in extra-high water cut reservoirs. J Petrol Sci Eng 154(April):315-321

Du X, Ding W, Jiao B, Zhou Z, Xue M, Liu T (2019) Characteristics of hydrocarbon migration and accumulation in the Linhe-Jilantai area, Hetao Basin China. Pet Sci Technol 37(21):2182-2189

Hu YY, Xianhua GT (2015) Reservoir forming mechanism of remaining oil re-enrichment in water flooding reservoir. Petroleum Geology and Recovery Efficiency 22(04):79-86

Han D (2010) Discussions on concepts, countermeasures and technical routes for the redevelopment of high water-cut oilfields. Shiyou Kantan Yu Kaifa/Pet Explor Dev 37(5):583-591

He J, Zhu L, Liu C, Bai Q (2019) Optimization of the oil agglomeration for high-ash content coal slime based on design and analysis of response surface methodology (RSM). Fuel 254(March):115560

Jacotă DR (2015) Uncertainty and Risk Evaluation in the Tertiary Migration of Abandoned Oil Reservoirs. BULETINUL Universităţii Petrol - Gaze dinPloieşti Seria Tehnică 9:109-116

Jacota D (2014) Gravity drainage-a main pillar in the tertiary oil migration in abandoned reservoirs: I: basic concepts. Pet Gas Univ Ploiesti Bull Tech Ser 66(4):91-98

Kang W, Shao S, Yang H, Chen C, Hou X, Huang Z, Zhao H, Aidarova S, Gabdullin M (2019) The effect of stepwise increasing of water injection rates on enhanced oil recovery after preformed particle gel treatment. J Petrol Sci Eng 182:106239

Karami HR, Keyhani M, Mowla D (2016) Experimental analysis of drag reduction in the pipelines with response surface methodology. J Petrol Sci Eng 138:104-112

Kumar A, Saw RK, Mandal A (2019) RSM optimization of oil-in-water microemulsion stabilized by synthesized zwitterionic surfactant and its properties evaluation for application in enhanced oil recovery. Chem Eng Res Des 147:399-411

Kumar S, Mandal A (2017) A comprehensive review on chemically enhanced water alternating gas/CO2 (CEWAG) injection for enhanced oil recovery. J Petrol Sci Eng 157:696-715

Li W, Wei F, Xiong C, Ouyang J, Zhao G, Shao L, Dai M (2019) A novel binary compound flooding system based on DPG particles for enhancing oil recovery. Arab J Geosci 12(7):256

Liu N, Ju B, Chen X, Brantson ET, Mu S, Yang Y, Wang J, Mahlalela BM (2019) Experimental study of the dynamic mechanism on gas bubbles migration, fragment, coalescence and trapping in a porous media. J Petrol Sci Eng 181:106192

Minescu F, Popa C, Grecu D (2010) Theoretical and practical aspects of tertiary hydrocarbon migration. Pet Sci Technol 28(6):555-572

Nasri Z, Mozafari M (2018) Multivariable statistical analysis and optimization of Iranian heavy crude oil upgrading using microwave technology by response surface methodology (RSM). J Pet Sci Eng 161(2017):427-444

Popa C, Jacotă D (2016) Computational methods for reservoir characterization in studying the efficiency of the tertiary migration of the tertiary in abandoned oil reservoirs. International Multidisciplinary Scientific GeoConference: SGEM: SurveyingGeology \& mining Ecology Management 3:777-784

Shen W, Pang X, Jiang F, Zhang B, Huo Z, Wang Y, Hu T, Wang G (2016) Accumulation model based on factors controlling Ordovician hydrocarbons generation, migration, and enrichment in the Tazhong area, Tarim Basin NW China. Arab J Geosci 9(5):347

Wang J, Liu S, Li J, Zhang Y, Gao L (2011) Characteristics and causes of Mesozoic reservoirs with extra-low permeability and high water cut in northern Shaanxi. Pet Explor Dev 38(5):583-588

Wang Y, Liu L, Ji H, Song G, Luo Z, Li X, Xu T, Li L (2018) Origin and accumulation of crude oils in Triassic reservoirs of WuerheFengnan area (WFA) in Junggar Basin, NW China: constraints from molecular and isotopic geochemistry and fluid inclusion analysis. Mar Pet Geol 96:71-93

Wang J, Lou Z, Zhu R, Jin A (2019) The migration of hydrocarbons: a case from the Shahejie formation of the Wenliu area of Bohai Bay Basin China. Pet Sci Technol 37(1):38-49

Wang L, Kong H, Qiu C, Xu B (2019) Time-varying characteristics on migration and loss of fine particles in fractured mudstone under water flow scour. Arab J Geosci 12(5):159

Wang X, Fang H, Fang S (2020) An integrated approach for exploitation block selection of shale gas-based on cloud model and grey relational analysis. Resources Policy 68:101797

Wang X, Yang Y, Xi W (2016) Microbial enhanced oil recovery of oilwater transitional zone in thin-shallow extra heavy oil reservoirs: a case study of Chunfeng Oilfield in western margin of Junggar Basin NW China. Pet Explor Dev 43(4):689-694

Xu S, Hao F, Xu C, Zou H, Zhang X, Zong Y, Zhang Y, Cong F (2019) Hydrocarbon migration and accumulation in the northwestern Bozhong subbasin, Bohai Bay Basin, China. J Petrol Sci Eng 172(66):477-488

Xu Z, Liu L, Jiang S, Wang T, Wu K, Feng Y, Xiao F, Chen Y, Chen Y, Feng C (2019) Migration model of hydrocarbons in the slope of the superimposed foreland basin: a study from the South Junggar, NW China. J Petrol Sci Eng 182:106337

Zhang H, Chen S, Huang H, Wu B, Wang L, Lu J (2017) Overpressure water zone influence on hydrocarbon migration and oil reservoir distribution in low Cretaceous formations of Yinger sag China. Pet Sci Technol 35(3):306-312

Zhao F, Su W, Hou J, Xi Y, Zhao T (2018) Experimental study on feasibility and mechanisms of $\mathrm{N}_{2} / \mathrm{CO}_{2}$ huff-n-puff in the fracturedcavity reservoir. Arab J Geosci 11(21):660

Publisher's Note Springer Nature remains neutral with regard to jurisdictional claims in published maps and institutional affiliations. 